\title{
Freqüência da Mutação Gene da Síndrome do Estresse Suíno e sua Associação com Características Reprodutivas em Marrãs Híbridas
}

\author{
Simone Eliza Facioni Guimarães ${ }^{1}$, Ricardo Frederico Euclydes ${ }^{1}$
}

\begin{abstract}
RESUMO - O objetivo deste trabalho foi determinar a freqüência do gene causador da síndrome do estresse em suíno (PSS) e sua associação com características reprodutivas em marrãs híbridas. Setenta e duas marrãs híbridas Landrace x Large White, provenientes de granjas comerciais localizadas na região de Ponte Nova - Minas Gerais, foram analisadas para a presença da mutação PSS. No diagnóstico da mutação feito por reação em cadeia da polimerase - polimorfismo de comprimento de fragmentos de restrição (PCR-RFLP), o fragmento de 659pb do gene ryr-1 foi amplificado e, nos mutantes a substituição de citosina por timina, que acarreta mudança de aminoácidos da proteína madura de arginina para cisteína nos animais afetados, foi identificado. Dados relativos ao número de leitões nascidos vivos, leitões nascidos com baixa viabilidade e leitões natimortos por leitegada, peso médio dos leitões ao nascer e repetições de cio foram analisados. Do total de marrãs analisadas, foram encontradas 13,88\% de marrãs heterozigotas e nenhuma homozigota recessiva. Não houve efeito dos genótipos sobre as características analisadas.
\end{abstract}

Palavras chave: PCR-RFLP, marrãs híbridas, PSS

\section{Frequency of the Porcine Stress Sindrome Gene Mutation and its Association with Reproductive Traits in Crossbred Gilts}

\begin{abstract}
The objective of this work was to determine the frequency of the porcine stress sindrome (PSS) gene mutation and its association with reproductive traits in crossbred gilts. Seventy two crossbred Landrace x Large White females from commercial farms of Ponte Nova region location - Minas Gerais State, were analyzed for the PSS mutation. The mutation diagnose was made by polimerase chain reaction - restriction fragment length polimorphism, where the $659 \mathrm{pb}$ fragment from the ryr-1 gene was amplifyied, and in the mutants the substitution of cytosine by thimine, that leads to the change in the mature protein amino acids from arginine to cysteine in the affected animals, was identified. Data relative to the number of piglets born alive, born alive with low viability and dead piglets per litter, average piglets born weight and estrus return were analyzed. From the total gilts, 13,88\% of heterozygous gilts and none recessive homozygous were found. There was no effect of the genotypes on the analyzed traits.

Key Words: PCR-RFLP, crossbred gilts, PSS
\end{abstract}

\section{Introdução}

A síndrome do stress suíno (PSS) é miopatia hereditária, na qual ocorre a contratura muscular esquelética, acompanhada de hipermetabolismo e elevação da temperatura corporal. Esses sintomas podem ser provocados por anestésicos inalantes e relaxantes da musculatura esquelética. Em suínos homozigotos para a mutação, a miopatia pode também ser desencadeada por estresse. As perdas econômicas na indústria incluem morte dos animais portadores e desenvolvimento pós-abate de carnes pálidas, moles e exudativas, complexo conhecido por PSE - Pale, Soft, Exudative, em animais susceptíveis a PSS (O'BRIEN, 1987).

O padrão de herança da PSS é monogênico e autossômico, mas a sua dominância depende da ca- racterística a ser considerada (OLLIVIER et al., 1975). O padrão reflete a dosagem do gene da PSS necessária para exibir a característica. A expressão deste gene pode ser modificada por fatores fenotípicos, ambientais, farmacológicos e de manejo (O'BRIEN, 1995).

Apesar de as análises do gene ryr-1 (receptor rianodina) mostrarem que a mutação PSS surgiu de um único animal fundador, por volta do início do século XX (FUJII et al., 1991), esta mutação está hoje presente em cerca de $25 \%$ dos suínos multiplicadores na América do Norte e na Europa (O'BRIEN et al., 1993). De acordo com O'BRIEN (1995), a rápida disseminação da mutação pela indústria suína em tão poucas décadas é o resultado de fatores como o pequeno estoque suíno existente para aumento de produção de carne, a introdução cons- 
tante de diferentes raças e linhagens nas criações, o fato de a mutação PSS ter efeitos favoráveis na musculatura, produzindo carcaça mais magra, com melhor distribuição de gordura, e a não-existência de penalidades para os produtores que produzem suínos com características deletérias associadas com a mutação PSS (ex.: carnes PSE).

Após a descoberta da mutação no gene ryr-1 por FUJII et al. (1991), desenvolveu-se um teste específico e definitivo para o diagnóstico desta alteração, o qual implica na amplificação por PCR (reação em cadeia da polimerase), da região gênica afetada, e subseqüente clivagem por enzimas de restrição que reconhecem unicamente o sítio modificado geneticamente.

Esta técnica é utilizada para estudo de outros genes em animais, vegetais e humanos, sendo também chamada de PCR-RFLP (reação em cadeia da polimerase - polimorfismo no tamanho dos fragmentos de restrição) (GUIMARÃES e PINHEIRO, 1996). O'BRIEN (1995) afirma que esta tecnologia tem precisão de $99 \%$ na identificação não apenas dos homozigotos mutantes, mas também dos heterozigotos portadores e assintomáticos. Esta técnica se baseia na amplificação in vitro do DNA genômico da região em que se encontra a mutação responsável pela síndrome, que é caracterizada pela substituição da citosina 1843 pela timina ${ }^{1843}$, resultando na troca da arginina ${ }^{615}$ por uma cisteína ${ }^{615}$, na proteína madura resultante da transcrição do alelo mutado. Após a amplificação, a mutação é reconhecida por endonucleases de restrição. Neste trabalho utilizou-se a BsiHKA I.

Juntamente com os efeitos favoráveis na musculatura, como a produção de carcaças mais magras, com melhor distribuição de gordura, a PSS tem efeitos deletérios, como a morte de animais homozigotos. Em ambientes com estresse controlado, porém, a síndrome pode chegar a não se desenvolver, mesmo nos homozigotos mutantes. A maior perda dentro da suinocultura, acarretada pela mutação PSS no estado homozigoto, consiste no desenvolvimento de carnes PSE.

Objetivou-se detectar e levantar a freqüência do gene PSS, em animais da região de Ponte Nova Minas Gerais, e avaliar seus efeitos sobre características reprodutivas, em uma amostra de matrizes híbridas pertencentes a granjas comerciais localizadas nessa região.

\section{Material e Métodos}

Utilizando-se EDTA como anticoagulante, coletaram-se $5 \mathrm{~mL}$ de sangue por venopunção no sinus orbital de 72 matrizes híbridas Landrace (L) x Large White (LW) de granjas comerciais situadas na região de Ponte Nova - MG. Estas fêmeas foram separadas em três linhas distintas; a linha L1 foi composta por fêmeas L x LW de variedade comercial; a linha L2 foi representada por fêmeas produto dos acasalamentos da linha L1 com outra variedade comercial introduzida no rebanho e também produzida a partir de animais $\mathrm{L}$ x LW; e, finalmente, a linha L3 era produto dos acasalamentos de animais L2.

Após a coleta, as amostras foram transportadas para o Laboratório de Melhoramento Animal do Departamento de Zootecnia da UFV e mantidas em geladeira para a extração do DNA genômico. De cada fêmea coletaram-se também os dados referentes ao número de leitões nascidos vivos, combaixa viabilidade enatimortos por leitegada, bem como o peso médio dos leitões vivos ao nascer e as repetições de cio das fêmeas.

Para a extração do DNA, utilizou-se a técnica do fenol:clorofórmio descrita por SAMBROOK et al. (1989). Após a extração, o DNA foi quantificado e diluído na concentração de aproximadamente $20 \mathrm{ng} / \mu \mathrm{L}$, para ser então utilizado nas amplificações. Basicamente os sistemas de PCR foram constituídos de $20 \mathrm{ng}$ de DNA genômico, tampão ( $\mathrm{KCl} 50 \mathrm{mMe}$ TRIS $20 \mathrm{mM} \mathrm{pH} \mathrm{8,3),} 4 \mathrm{mM} \mathrm{MgCl}_{2}, 0,2$ $\mathrm{mM}$ dNTPs, 0,2 $\mu \mathrm{M}$ de cada primer (O'BRIEN, 1995), 1U Taq polimerase e água Milli-Q na quantidade suficiente para $20 \mu \mathrm{L}$. O programa de amplificação constou dos seguintes passos: $94^{\circ} \mathrm{C} / 1 \mathrm{~min}$., $68^{\circ} \mathrm{C} / 1 \mathrm{~min}$. e $72^{\circ} \mathrm{C} / 1 \mathrm{~min}$., repetidos por 33 vezes.

Ao final dos ciclos de PCR, analisaram-se $2 \mu \mathrm{L}$ do material por eletroforese em géis de poliacrilamida a $5 \%$ (PAGE 5\%), corados por brometo de etídeo e visualizados em transiluminador de luz ultra-violeta, para confirmar a amplificação pela presença de um fragmento de $659 \mathrm{pb}$ (pares de base). Após as amplificações, submeteram-se $2 \mu \mathrm{L}$ do produto amplificado às análises de restrição para diagnóstico do alelo mutante. Para diagnóstico da mutação, utilizou-se a endonuclease BsiHKA I (New England Biolabs, Inc.), cujo sítio de restrição está esquematizado na Figura 1a, que, além de reconhecer o sítio polimórfico para a mutação, reconhece e cliva um sítio monomórfico 
a) $5^{\prime} \ldots \mathrm{G} \quad \mathrm{W} \mathrm{G} \mathrm{C} W \downarrow^{\mathrm{C} \ldots . .33^{\prime}}$

$$
3^{\prime} \text {....C } \uparrow \mathrm{W} \mathrm{C} \text { G W G...5' }
$$

b)

$$
135 \mathrm{pb} \Downarrow \quad 524 \mathrm{pb}
$$

$659 \mathrm{pb}$

c)

\begin{tabular}{lllll}
$135 \mathrm{pb}$ & $\Downarrow$ & $358 \mathrm{pb}$ & $\downarrow$ & $166 \mathrm{pb}$ \\
\hline
\end{tabular}

$659 \mathrm{pb}$

Figura 1 - a) as setas indicam o sítio de restrição reconhecido pela enzima BsiHKA I. A letra W indica adenina ou timina. b) esquema representando o sítio de corte monomórfico $(\Downarrow)$ da enzima BsiHKA I no fragmento gênico amplificado de $659 \mathrm{pb}$, utilizado na detecção da mutação PSS, cuja restrição origina dois fragmentos menores, 135pb e 524pb; c) representação do sítio monomórfico $(\downarrow)$, e o nucleotídeo que, quando mutado $(\downarrow)$, gera fragmentos de $135 \mathrm{pb}, 358 \mathrm{pb}$ e $166 \mathrm{pb}$, o que permite então reconhecer os alelos afetados.

Figure 1- a) arrows indicate BSiHKA I cleavage site. Letter $W$ indicates adenine or thimine. b) representation of BSIHKA I monomorphic cleavage site $(\downarrow)$ in the $659 \mathrm{pb}$ fragment amplifyed to detect PSS mutation, this cleavage generates two fragments, $135 \mathrm{bp}$ and $524 \mathrm{bp}$. c) in is shown the monomorphic $(\downarrow)$ and the polymorphic site $(\downarrow)$, that diagnoses the affected allele, generating three fragments, 135bp, 358bp and 166bp.

presente em todos os animais, gerando o padrão de restrição esquematizado nas Figuras $1 \mathrm{~b}$ e 1c. Posteriormente, as amostras foram analisadas por PAGE $5 \%$ corado pelo brometo de etídeo ou pelo nitrato de prata, para diagnóstico dos genótipos.

\section{Análise estatística}

As freqüências gênicas entre as três diferentes linhas foram comparadas por Qui-quadrado e os dados de produção de leitegadas e de repetição de cios das porcas foram analisados pelo pacote computacional SAEG (Sistema de Análises Estatísticas e Genéticas), descrito por EUCLYDES(1989), sendo a significância estabelecida em 5\% para todas as análises.

Os dados foram comparados por análise de variância, segundo um modelo que continha os efeitos de linha (L1, L2 e L3) e genótipo do gene PSS (homozigoto normal e heterozigoto).

\section{Resultados e Discussão}

Das 72 matrizes híbridas analisadas, $10(13,88 \%)$ apresentaram genótipo heterozigoto detectado por PCR-RFLP. Não foram encontradas fêmeas homozigotas recessivas. Esta freqüência gênica está de acordo com citações da literatura (O'BRIEN, 1993). Apesar de não terem sido detectados animais homozigotos recessivos na população, estes podem estar sendo produzidos pelo acasalamento das marrãs com machos heterozigotos. Como a mutação altera apenas um locus, a probabilidade de um animal heterozigoto, quando acasalado com um animal normal, transmitir a sua progênie é de $50 \%$, já no acasalamento entre dois animais heterozigotos, $25 \%$ da progênie será normal, $50 \%$ portadora e $25 \%$ afetada. Portanto, o diagnóstico da mutação deve ser feito com freqüência, para que os prejuízos advindos das mortes e das carnes PSE possam ser quantificados e, então, minimizados por programas de controle da mutação.

Alguns autores (O'BRIEN et al., 1993; O'BRIEN 1995) citam que, devido aos efeitos aparentemente benéficos desta mutação sobre as características de carcaça dos animais portadores, vários fatores devem ser considerados antes de serem desenvolvidas estratégias para uso ou erradicação da mutação PSS. Pode ser vantajoso o desenvolvimento de animais heterozigotos destinados unicamente ao abate, pelo uso de cachaços reconhecidamente portadores e fêmeas sabidamente livres. Como os lucros dos criadores são geralmente pequenos, o ganho obtido na produção de animais mais magros, musculosos e com menor teor de gordura poderia trazer benefícios aos suinocultores, pela tipificação das carcaças, principalmente quando se sabe que os riscos de os heterozigotos desenvolverem PSE são mínimos.

Sabe-se, também, que em criações onde o estresse é controlado, a síndrome pode chegar a não se desenvolver, mesmo nos animais homozigotos mutantes, 
sendo nestas situações as maiores perdas advindas do desenvolvimento pós-abate da PSE. Contudo, quando o sistema de manejo praticado não evita o estresse, além das perdas econômicas por PSE, os criadores devem também contar com perdas relativas as mortes dos animais homozigotos, que podem ser, em alguns casos, mais vultuosas que os lucros advindos do abate dos heterozigotos. Neste aspecto, de acordo com A. C. CLUTTER, 1998 (comunicação pessoal), a estratégia adotada por criadores e associações norte-americanas é a de erradicação total da mutação.

Portanto, o custo/benefício da mutação deve ser analisado não somente quanto ao aspecto genético, mas principalmente quanto aos aspectos econômicos envolvidos na manutenção da suinocultura regional. Nestas análises de custo, seriam considerados o valor de cada animal perdido em manejo ou transpor-

Tabela 1 - Número e porcentagem de fêmeas normais e heterozigotas para a mutação PSS nas linhas L1, L2 e L3 e na amostra total estudada

Table 1 - Number and percentage of normal and heterozygous females for the PSS mutation in lines L1, L2 and L3 and in the total analyzed sample

\begin{tabular}{lccc}
\hline $\begin{array}{l}\text { Linha } \\
\text { Line }\end{array}$ & $\begin{array}{c}\text { Normal }(\%) \\
\text { Normal }\end{array}$ & $\begin{array}{c}\text { Heterozigota }(\%) \\
\text { Heterozygote }\end{array}$ & Total \\
\hline L1 & $15(93,75)^{\mathrm{a}}$ & $1(6,25)^{\mathrm{a}}$ & 16 \\
L2 & $30(78,95)^{\mathrm{a}}$ & $8(21,05)^{\mathrm{a}}$ & 38 \\
L3 & $17(94,45)^{\mathrm{a}}$ & $1(5,50)^{\mathrm{a}}$ & 18 \\
Total & $62(86,00)$ & $10(13,88)$ & 72 \\
\hline
\end{tabular}

Letras iguais nas colunas indicam semelhança estatística a $5 \%$.

Equal letters within columns indicate statistical similarity at $5 \%$. te e a diminuição do valor de cada carcaça afetada pela PSE, entre outros fatores.

Nas publicações sobre o tema, muito pouco tem sido relatado a respeito dos animais homozigotos recessivos ou heterozigotos, com respeito ao desempenho reprodutivo. Neste experimento, como demostrado nas Tabelas 1 e 2, não se encontrou significância entre os dados reprodutivos coletados e a presença do gene mutante. Pode ser observado na Tabela 1 que não há diferença estatística $(\mathrm{P}>5 \%)$ na freqüência de genótipos heterozigotos, quando se consideram as três linhas separadas, L1, L2 e L3.

A Tabela 2 mostra que as características reprodutivas avaliadas, além de serem semelhantes entre as linhas analisadas, encontram-se também dentro das médias estabelecidas para rebanhos comerciais, estando o número médio de leitões nascidos por leitegada entre $11,80 \pm 1,96$ para as normais e 9,96 $\pm 2,83$ para as fêmeas heterozigotas. O peso em gramas dos leitões por leitegada mostrou-se, também, dentro da normalidade e semelhante entre os dois grupos, sendo de $1433,81 \pm 0,88$ para as normais e 1458,75 $\pm 241,04$ para as heterozigotas. Com relação ao número de leitões natimortos, mumificados e com baixa viabilidade, a tendência de similaridade se manteve, sendo as médias de 1,25 0 , 88 leitões para as fêmeas normais e $0,73 \pm 0,80$ para as heterozigotas. Para os dados relativos às repetições de cio, a média para as fêmeas normais, $0,70 \pm 0,67$, foi também estatisticamente semelhante à apresentada para as fêmeas heterozigotas, $0,58 \pm 0,71$.

Quando se analisam os padrões reprodutivos das

Tabela 2 - Comparação entre fêmeas normais e heterozigotas para a mutação PSS e entre as linhas L1, L2 e L3 com respeito a características reprodutivas analisadas

Table 2 - Comparition among normal and heterozygous females for the PSS mutation and among line L1, L2 and L3 regarding to the analysed reproductive traits

\begin{tabular}{|c|c|c|c|c|}
\hline Linha & NLL* & PL* & $\mathrm{BV}^{*}$ & $\mathrm{RC}^{*}$ \\
\hline \multicolumn{5}{|l|}{ Line } \\
\hline Normal & $11,80^{\mathrm{a}} \pm 0,25$ & $1433,81^{\mathrm{a}} \pm 22,48$ & $1,25^{\mathrm{a}} \pm 0,11$ & $0,70^{\mathrm{a}} \pm 0,08$ \\
\hline Heterozigota & $9,96^{\mathrm{a}} \pm 0,89$ & $1458,75^{\mathrm{a}} \pm 76,28$ & $0,73^{\mathrm{a}} \pm 0,25$ & $0,58 \pm 0,22$ \\
\hline \multicolumn{5}{|l|}{ Heterozygote } \\
\hline $\mathrm{L} 1$ & $11,34^{\mathrm{a}_{ \pm}}, 0,51$ & $1429,72^{a} \pm 43,85$ & $1,30^{\mathrm{a}} \pm 0,20$ & $0,58^{a_{ \pm}}+16$ \\
\hline $\mathrm{L} 2$ & $12,21^{a_{ \pm}}{ }_{0,37}$ & $1430,86^{\mathrm{a}_{ \pm}}{ }_{27,00}$ & $1,30^{\mathrm{a}_{ \pm} 0,13}$ & $0,81^{\mathrm{a}_{ \pm 0}, 13}$ \\
\hline $\mathrm{L} 3$ & $11,88^{\mathrm{a}} \pm 0,40$ & $1458,96^{\mathrm{a}} \pm 54,65$ & $1,07^{a_{ \pm}} \pm 0,21$ & $0,44^{\mathrm{a}_{ \pm 0}}{ }^{16}$ \\
\hline
\end{tabular}

${ }^{*}$ Médias nas colunas, seguidas de letras diferentes são diferentes $(P<0,05)$.

NLL: média e desvio-padrão do número de leitões nascidos por leitegada; PL: média e desvio padrão do peso dos leitões por leitegada; BV: média e desvio-padrão obtido da soma do número de leitões natimortos, mumificados e com baixa viabilidade por leitegada: RC: média e desvio padrão do número de cios repetidos.

* Means, within a column, followed by different letters are different $(P<.05)$.

NLL: pigs per litter mean number and standard deviation; PL: mean weight of pigs per litter and standard deviation; BV: pigs born dead, mumified and low viability born pigs per litter mean number and standard deviation; $R C$ : retun estrus mean number and standard deviation. 
mesmas fêmeas, mas separadas em linhas (L1, L2 e L3), a semelhança com os dados apresentados por granjas na região de coleta é mantida, e a ausência de diferença estatística continua a ser observada. Considerando-se, respectivamente, as linhas L1, L2 e L3, constatou-se que as médias para o número de leitões nascidos por leitegada foi de $11,34 \pm 2,05 ; 12,21 \pm 2,31$; e $11,88 \pm 1,72$; o peso em gramas dos leitões por leitegada obteve as médias de 1429,72 $\pm 172,34$; $1430,86 \pm 166,34$; e $1458,96 \pm 231$; a média obtida para o número de leitões natimortos, mumificados e com baixa viabilidade foi de $1,30 \pm 0,80 ; 1,30 \pm 0,84 ;$ e $1,07 \pm 0,90$; e a média de cios repetidos mostrou-se semelhante entre as linhas, sendo $0,58 \pm 0,64 ; 0,81 \pm 0,83 ; \mathrm{e} 0,44 \pm 0,70$.

Apesar das semelhanças estatísticas encontradas, é necessário esclarecer que a amostra deve ser aumentada, para que seja realmente representativa, devendo constar não apenas fêmeas híbridas, mas também a de raças definidas (Landrace, Large White, entre outras). Com maior número de animais analisados, será possível traçar perfil da síndrome na região. É interessante acrescentar que a associação feita com a mutação PSS e a raça Pietrain, apesar de forte e verdadeira, não é a única a ser considerada, pois na amostra Landrace $x$ Large White, estudada neste trabalho, encontraram-se altas porcentagens de animais heterozigotos (Tabela 1).

\section{Conclusões}

A aplicação de testes que permitam identificar a mutação PSS com alta precisão será fundamental para o levantamento dos efeitos deste gene na suinocultura regional, pois evitará que animais homozigotos mutantes se espalhem pelos plantéis, o que pode facilmente acontecer pelo uso de varrões e matrizes diagnosticados como falso-negativos por testes de pouca sensibilidade. Entre os testes atualmente disponíveis, aqueles com base na PCR-RFLP parecem ser os mais indicados, pela alta precisão (99\%), pela grande rapidez e pelos baixos custos.

\section{Referências Bibliográficas}

EUCLYDES, R.F. 1989. Manual de utilização do sistema SAEG (Sistema de Análises Estatísticas e Genéticas). Viçosa, 130p.

FUJII, J., OTSU, K., ZORZATO, F. et al. 1991. Identification of a mutation in the porcine ryanodine receptor associated with malignant hyperthermia. Science, 253: 448-451.

GUIMARÃES, S.E.F., PINHEIRO, L.E.L. 1996. Princípios Básicos da Genética Molecular e sua Aplicação em Melhoramento Animal; In: Melhoramento Genético Aplicado à Produção Animal. p.354-373. Editor: Jonas Carlos Campos Pereira. 2.ed. Belo Horizonte. Editora da UFMG.

O'BRIEN, P.J. 1987. Etiopathogenetic defect of malignant hyperthermia: hipersensitive calcium-release channel of skeletal muscle sarcoplasmic reticulum. Vet Res Commun, 11: 527-559.

O'BRIEN, P.J., ZHANG, X., SHEN, H. et al. 1993. Porcine stress syndrome: demonstration of a coste effective protocol for large scale, DNA-based diagnosis of the etiologic mutation in 10,000 breeding stock of various breeds. JAVMA, 203: 842-851.

O'BRIEN, P.J., BALL, R.O., MACLENNAN, D.H. Effect of heterozigosity for the mutation causing porcine stress syndrome on carcass quality and live performance characteristics. INTERNATIONAL PIG VET SOCIETY CONGRESS, 13, Guelph, 1994. Proceedings... Guelph, p.481, 1994.

O'BRIEN, P.J. 1995. The causative mutation for porcine stress syndrome. The Compendium Feb., 257-295.

OLLIVIER, L., SELLIER, P., MONIN, G. 1975. Determinisme genetique du syndrome d'hyperthermie maligne chez le porc de Piétrain. Ann Genet Sel Anim., 7:159-166.

SAMBROOK, J., FRITISCH, E.F., MANIATS, T. 1989. Molecular cloning: a laboratory manual. Cold Spring Harbor Laboratory, Cold Spring Harbor, NY, 626pp.
Recebido em: 13/01/98

Aceito em: 26/11/98 